\title{
A EVOLUÇÃO DA RESPONSABILIDADE CIVIL: DA OBJETIVAÇÃO DA RESPONSABILIDADE À PREVENÇÃO DE DANOS
}

\author{
THE EVOLUTION OF CIVIL RESPONSIBILITY: FROM THE OBJECTIVATION OF \\ RESPONSIBILITY TO DAMAGE PREVENTION
}

\author{
Fábio da Silva Veiga ${ }^{1}$ \\ Lourenço de Miranda Freire Neto ${ }^{2}$ \\ Fernando Virmond Portela Giovannetti ${ }^{3}$
}

\section{RESUMO}

conceito de responsabilidade civil passou por profundas transformações durante 0 século XX, muito por conta das transformações verificadas no próprio tecido social, notadamente com o fenômeno da industrialização. A clássica concepção de

\footnotetext{
${ }^{1}$ Doutor em Direito Empresarial (Ordenação Jurídica do Mercado) pela Universidade de Vigo, Espanha. Aprovado no Estágio de Pós-doutorado da Faculdade de Direito da Universidade do Estado do Rio de Janeiro - UERJ; Pesquisador do Programa de Doutorado em Direito Empresarial na Universidad de Alcalá (Madrid, Espanha) com Bolsa DPE CAPES. Mestre em Direito dos Contratos e da Empresa, pela Universidade do Minho - Braga, Portugal - área de concentração: Responsabilidade dos administradores no âmbito da Falência/Insolvência. Especialista em Direito dos Contratos e da Empresa pela Universidade do Minho.

${ }^{2}$ Doutorando em Direito Político e Econômico pela Universidade Presbiteriana Mackenzie. Mestre em Direito pela Universidade Católica de Pernambuco. Bacharel em Direito pela Universidade Federal da Paraíba. Professor licenciado da Universidade Federal da Paraíba. Atua nas áreas de direito médico, direito da saúde (seguridade social), direito constitucional, direito civil, direito processual civil e prática jurídica civil. Advogado inscrito na Ordem dos Advogados do Brasil Seccional da Paraíba.

${ }^{3}$ Mestrando em Direito Empresarial e Cidadania pelo UNICURITIBA. Graduado em Direito pela Faculdade de Direito da Universidade Federal do Paraná.
} 
responsabilidade civil subjetiva, calcada na culpa, foi cedendo espaço para as diversas hipóteses hoje previstas de responsabilidade objetiva, fundada nas teorias do risco. Entretanto, para além da dicotomia "teoria da culpa" e "teoria do risco", o presente artigo pretende abordar sobre a tendência doutrinária de se discutir a mudança na perspectiva funcional da responsabilidade civil, de reparatória para a preventiva. Para esse estudo, é imprescindível a utilização do instrumental fornecido pela escola da Análise Econômica do Direito.

PALAVRAS-CHAVE: responsabilidade civi; prevenção; análise econômica.

\section{ABSTRACT}

The concept of civil responsibility underwent profound transformations during the twentieth century, largely due to the transformations in the social fabric, especially with the phenomenon of industrialization. The classic conception of subjective civil liability, based on guilt, has given way to the various hypotheses presently provided for by objective responsibility, based on theories of risk. However, in addition to the dichotomy "theory of guilt" and "theory of risk", this article aims to address the doctrinal tendency to discuss the change in the functional perspective of civil liability, from reparatory to preventive. For this study, it is essential to use the instruments provided by the School of Economic Analysis of Law.

KEYWORDS: civil liability; prevention; economic analysis.

\section{INTRODUÇÃO}

Nas civilizações antigas, não havia qualquer distinção entre responsabilidade civil e penal, nem mesmo entre responsabilidade individual e coletiva. Tampouco a noção de culpa era levada em consideração para fins de responsabilização de indivíduos ou grupos. 
Prevalecia a ideia de vingança privada, ou vendetta, em que o clã ou o grupo do ofendido ficavam encarregados de punir o ofensor - e o clã ou a família - do ofensor. No século XVIII a. C, com o Código de Hammurabi, e no século V a.C, com a Lei das XXII Tábuas, ocorreu substancial progresso na noção de responsabilidade, uma vez que foi conferida a noção de reciprocidade entre a ofensa e o castigo. Entretanto, não havia ainda a separação entre a responsabilidade civil e a penal ${ }^{4}$.

Já no século III, a. C, o Direito Romano passou a considerar, ainda que de forma rudimentar, a culpa como elemento da responsabilidade civil, introduzida pela lex Aqulia de damno5. Daí a origem da denominação classificatória "responsabilidade civil aquiliana", bastante difundida pela doutrina, embora seja ordinariamente utilizada para designar a responsabilidade civil extracontratual.

Foi com o iluminismo que a construção conceitual da responsabilidade civil ganhou contornos mais sólidos, diferenciando-a claramente da responsabilidade criminal e estabelecendo a culpa (em sentido amplo) como um dos seus pressupostos, ao lado do dano e o nexo causal da conduta perpetrada pelo ofensor.

Destarte, no direito oitocentista a culpa era pressuposto necessário da responsabilidade civil, de sorte que não haveria obrigação de indenizar o dano sem a existência da culpa do agente ${ }^{6}$.

Entretanto, desde o final do século XIX e no século XX percebeu-se a insuficiência do modelo de responsabilidade civil calcado exclusivamente na culpa do agente, dadas as substanciais transformações sociais durante o período. 0 desenvolvimento da sociedade de mercado e industrial trouxe a reboque o risco das atividades; os danos provocados passaram a ser superlativos e sua justa reparação passou a ser vindicada pela sociedade.

$4 \quad$ NORONHA, Fernando. Direito das Obrigações: Fundamentos do Direito das Obrigações; Introdução à Responsabilidade Civil. $2^{\mathrm{a}}$ ed. v.1. São Paulo: Editora Saraiva, 2007, p. 528

$5 \quad$ Ibid., p. 528.

$6 \quad$ Ibid., p. 533. 
Diante da complexidade decorrente das transformações sociais, com o incremento dos riscos nas atividades, a exigência de comprovação da culpa do agente causador de danos poderia constituir tarefa extremamente difícil, acarretando em decisões injustas em desfavor das vítimas de danos que não conseguissem comprovar o dolo ou a culpa.

Nesse sentido, o jurista Fernando Noronha ensina:

No que tange à responsabilidade civil, a revolução industrial trouxe enorme agravação dos riscos a que as pessoas antigamente estavam sujeitas, fazendo crescer as demandas no sentido de eficaz reparação deles. A exigência, feita no século XIX, de uma conduta culposa, como pressuposto da responsabilidade, não se coaduna com necessidade social de assegurar a reparação desses danos, ainda que o causador tenha procedido sem culpa. O direito tinha de deixar de preocupar-se só com o comportamento da pessoa responsável, precisava olhar o lado do lesado, tinha de se orientar, como afirma Jourdain (...) na direção do 'objeto da responsabilidade civil: a reparação dos danos'. ${ }^{7}$

Embora o Código Civil de 1916 tenha adotado o modelo oitocentista de responsabilidade civil, erigindo a culpa e o dolo como fundamento da obrigação de indenizar, durante todo o século $X X$ percebeu-se uma consistente tendência de objetivização da responsabilidade civil.

Em 1940, o saudoso jurista Orlando Gomes, em artigo publicado originalmente na Revista Forense, já refutava com veemência as posições consideradas tradicionais, segundo as quais a culpa era pressuposto da obrigação de reparar o dano. O jurista baiano identificava a tendência da objetivização da responsabilidade civil inclusive com a então flexibilização da individualização da culpa, em que se admitia as presunções de culpa em determinadas situações, ainda que não estivessem afastadas as concepções mais ortodoxas da responsabilidade subjetiva. Senão vejamos: 
Sendo juris et de jure a responsabilidade do agente é nitidamente objetiva. Em tais casos, a culpa é mero vocábulo. Porque aquele que a lei presume responsável pelo dano causado a outrem não pode eximir-se da responsabilidade provando que não é culpado. A presunção legal juris et de jure não comporta prova em contrário. É o que acontece com a responsabilidade por acidente do trabalho. O patrão é responsável pelo acidente, deve repará-lo, ainda que possa provar que não houve de sua parte culpa. A sua responsabilidade decorre em última análise, do fato de ser patrão. Nestes termos, a presunção absoluta de culpa apresenta-se como a consagração da teoria objetiva da responsabilidade em linguagem subjetivista $^{8}$.

Embora nítida a tendência de objetivação da responsabilidade civil, primeiramente verificada na edição de leis especiais, para casos específicos de maior risco, e posteriormente ampliada - em muito - com a edição do Código de Defesa do Consumidor em 1990 e do Código Civil de 2002, a responsabilidade civil subjetiva não foi deixada de lado pelo sistema, mas, ao contrário, coexiste com o sistema da responsabilidade objetiva ${ }^{9}$.

Inclusive a conjugação dos artigos 927 e 186, ambos do Código Civil, formam, nas palavras de Sérgio Cavalieri Filho, uma "cláusula geral da responsabilidade subjetiva"10, ao passo que o parágrafo único do artigo 927, conjugado com o artigo 187, do Código Civil, forma a "cláusula geral da responsabilidade objetiva". ${ }^{11}$ Não se trata, porém, de posição unânime da doutrina. ${ }^{12}$

\section{TEORIA DO RISCO E A CRESCENTE CONSTRUÇÃO DA RESPONSABILIDADE OBJETIVA NO BRASIL}

De acordo com a teoria do risco, ninguém é obrigado a suportar danos provocados por outrem, ainda que não houvesse culpa. Em certas ocasiões, basta o exercício de determinadas atividades promovidas por alguém, independentemente da

8 GOMES, Orlando. Culpa x Risco. Revista de Direito Civil Contemporâneo. v. 11, abr./jun. 2017 DTR|2017\1677; p. 4-5, 349/358.

9 CAVALIERI FILHO, Sérgio. Programa de Responsabilidade Civil. 10ª ed. São Paulo: Editora Atlas, 2012; p. 156.

$10 \quad$ lbid., p. 24.

Ibd., p.171.

TARTUCE, Flávio. Direito Civil. Direito das Obrigações e Responsabilidade Civil. v. 2. 12 a

ed. Rio de Janeiro: Editora Forense, 2016, p. 480/481. 
prática de atos ilícitos, para a caracterização da responsabilidade jurídica. Nesse sentido, preleciona Fernando Noronha:

\begin{abstract}
Como se vê, com o princípio do risco a ênfase é posta na causação, ou em casos especiais na mera atividade desenvolvida. Como justificativa desta responsabilidade sem culpa afirma-se que quem causa um dano, ou quem exerce determinadas atividades, deve reparar os danos sofridos pelas outras pessoas, porque se o ordenamento reconhece ou atribui a cada um de nós direitos incidentes sobre a nossa própria pessoa ou sobre determinados bens externos, não devem ser toleradas violações deles, mesmo quando a pessoa responsabilizada tenha procedido com todos os cuidados exigíveis. Se alguém tem de suportar o prejuízo, não deve ser a pessoa que era titular do direito. ${ }^{13}$
\end{abstract}

Para a teoria do risco, pouco importa a existência de qualquer juízo de valor ou de liame psicológico entre o fato e a conduta do agente que provocou o dano, tampouco se as precauções necessárias foram adotadas para evitar o perigo. Basta que o agente desempenhe determinadas atividades de risco previstas pela lei para, provocando o dano, ser responsabilizado e obrigado ao ressarcimento pelos prejuízos.

A teoria do risco, na legislação brasileira, já vinha sendo contemplada pontualmente desde a metade do século XX, ganhando certo destaque nas relações jurídicas do trabalho, especialmente em relação a acidentes de trabalho, que tornava muito frequentes e evidentes situações de injustiça ao exigir a difícil demonstração de culpa - em sentido lato - pelo empregado em face do empregador, diante da desigualdade técnica e econômica do trabalhador.

Já na década de 80, com a edição da lei n 6.938, de 30 de agosto de 1981, o poluidor passou a ser objetivamente responsável por atividades que, direta ou indiretamente, provocassem danos ao meio ambiente, senão vejamos:

Art. 14. [...]

$13 \quad$ NORONHA, 2007, p. 433. 
$\S 1^{\circ}$ - Sem obstar a aplicação das penalidades previstas neste artigo, é o poluidor obrigado, independentemente da existência de culpa, a indenizar ou reparar os danos causados ao meio ambiente e a terceiros, afetados por sua atividade. O Ministério Público da União e dos Estados terá legitimidade para propor ação de responsabilidade civil e criminal, por danos causados ao meio ambiente.

No âmbito do direito ambiental, o fator "risco" na responsabilidade civil objetiva é ainda mais expressivo, uma vez que restringe ainda mais as hipóteses de excludentes de responsabilidade (existentes em outros ramos do direito), justamente por conta da importância à proteção ao meio ambiente conferida pelo legislador e pelo constituinte, de sorte que doutrina e jurisprudência majoritárias entendem que, no caso, foi adotada a "teoria do risco integral". Nesse sentido, Flávio Tartuce faz a seguinte reflexão:

Percebe-se que, no caso de dano ambiental, os prejudicados são todos os
que vivem ambiente planeta Terra, pela própria concepção do meio ambiente
como bem difuso. Há, portanto, um dano coletivo, difuso, que atinge a todos
os seres. Mas o grande problema ou a grande dificuldade é justamente a
prova ou a presunção desse nexo de causalidade. Por essa dificuldade, e
lembrando que a responsabilidade objetiva é relacionada com o próprio
acesso à justiça, deve-se concluir que o nexo causal no caso de
responsabilidade civil por danos ambientais pode ser visualizada pela simples
atividade industrial, ou mesmo de outra natureza, explorada pela empresa
poluidora. ${ }^{14}$

A teoria do risco e a responsabilidade dela decorrente também ganhou bastante relevância no âmbito da Responsabilidade Civil do Estado.

$\mathrm{Na}$ época dos Estados absolutistas prevalecia a irresponsabilidade total do Estado, fundada na autoridade estatal perante os súditos e na soberania. ${ }^{15}$

Posteriormente, passou-se a admitir, de forma incipiente, a responsabilidade do Estado, quando o agente tiver agido de forma culposa. Ainda assim, costumava-se separar os atos de gestão e os atos de império: a responsabilidade civil do Estado só estaria presente nos primeiros, quando o Estado exercesse atividades em situação de igualdade com os particulares, ao passo que os atos de império seriam praticados 
com prerrogativas e privilégios especiais, regulados por um direito exorbitante do direito comum. ${ }^{16}$

A responsabilidade objetiva do Estado começou a levar em conta a teoria do risco inicialmente no direito francês, em que se distinguia a culpa individual do funcionário público da "culpa anônima" do serviço público prestado pelo Estado. Segundo a jus-administrativista Maria Sylvia Di Pietro, a responsabilidade civil do Estado está fundada no princípio da igualdade de todos perante os encargos sociais que encontra raízes no seguinte dispositivo da Declaração dos Direitos do Homem, de 178917:

Art. 13‥ Para a manutenção da força pública e para as despesas de administração é indispensável uma contribuição comum que deve ser dividida entre os cidadãos de acordo com suas possibilidades.

A autora paulista ressalta o que segue:

"O princípio significa que, assim como os benefícios decorrentes da atuação estatal repartem-se por todos, também os prejuízos sofridos por alguns membros da sociedade devem ser repartidos. Quando uma pessoa sofre um ônus maior do que o suportado pelos demais, rompese o equilíbrio que necessariamente deve haver entre os encargos sociais; para restabelecer esse equilíbrio, o Estado deve indenizar o prejudicado, utilizando recursos do erário" ${ }^{18}$.

A teoria objetiva da responsabilidade civil do Estado está presente no ordenamento jurídico brasileiro desde a Constituição de 1946, em seu artigo 194, sendo sucessivamente prevista nas constituições seguintes, estando contemplada na 
Constituição da República de 1988 a "teoria do risco administrativo" no seguinte dispositivo:

\begin{abstract}
Art. 37.
$[\ldots]$

$\S 6^{\circ}$ As pessoas jurídicas de direito público e as de direito privado prestadoras de serviços públicos responderão pelos danos que seus agentes, nessa qualidade, causarem a terceiros, assegurado o direito de regresso contra o responsável nos casos de dolo ou culpa.
\end{abstract}

Com efeito, se a atividade administrativa do Estado é exercida em benefício da coletividade, é justo também que todos respondam pelo seu ônus, normalmente custeados pelos impostos. Não teria sentido fazer com que um ou alguns administrados sofressem todas as consequências de eventuais danos decorrentes das atividades administrativas. ${ }^{19}$

Por fim, outra área do direito que merece destaque com relação à responsabilidade civil objetiva é o direito do consumidor. Em face da posição de vulnerabilidade técnica e econômica do consumidor nas relações de consumo, o Código de Defesa do Consumidor adotou como regra geral a "teoria do risco do negócio ou da atividade", ou ainda a "teoria do risco-proveito". Nesse sentido, Flávio Tartuce expõe o que segue,

Na verdade, o CDC adotou expressamente a ideia da teoria do risco-proveito, aquele que gera a responsabilidade sem culpa justamente por trazer benefícios ou vantagens. Em outras palavras, aquele que expões aos riscos outras pessoas, determinadas ou não, por dele tirar benefício, direto ou não, deve arcar com as consequências da situação de agravamento. Uma dessas decorrências é justamente a responsabilidade objetiva e solidária dos agentes envolvidos com a prestação ou fornecimento. ${ }^{20}$

19 CAVALIERI FILHO, 2012, p.256.

20 TARTUCE, 2015, p.132. 
Com efeito, nada mais justo que os fornecedores, enquanto agentes econômicos que se beneficiam das atividades de fornecimento de produtos ou serviços, suportem os riscos dessas atividades, já podendo-se falar em internalização de eventuais danos ou prejuízos causados aos consumidores, independentemente da comprovação de culpa.

O Direito do Consumidor ampara a expectativa legítima de que os produtos e serviços ofertados no mercado não apresentem periculosidade ou nocividade que possam provocar danos. Segundo Bruno Miragem,

"O respeito a esses interesses legítimos dos consumidores, como regra, não se submetem à verificação do critério da culpa do fornecedor acerca de eventuais prejuízos causados por seus produtos ou serviços, mas simplesmente na proteção da confiança social de adequação e segurança dos produtos introduzidos no mercado" 21.

De mais a mais, o ordenamento jurídico está permeado de diversas outras hipóteses em que prevê, de forma difusa, a distribuição dos riscos àqueles que provocam danos.

\section{RESPONSABILIDADE CIVIL SOB A PERSPECTIVA FUNCIONAL}

De acordo com a doutrina tradicional, a função mais essencial da responsabilidade civil é a reparação ou o ressarcimento por danos provocados, seja anulando um prejuízo econômico causado, seja minorando eventual sofrimento infligido (no caso do dano moral), ou ainda compensando a ofensa provocada. Tratase da função reparatória, fundamentada na proteção à esfera jurídica de cada pessoa.

De acordo com Fernando Noronha, 


\begin{abstract}
"as obrigações de responsabilidade civil têm essencialmente, mas não exclusivamente, uma finalidade estática, de proteção da esfera jurídica de cada pessoa, através da reparação dos danos por outrem causados, tutelando um interesse do credor que se pode chamar de expectativa de preservação da situação atual (ou de manutenção do status quo). Contudo, se essa finalidade (dita função reparatória, ressarcitória ou indenizatória) é a primacial, a responsabilidade civil desempenha outras importantes funções, uma sancionatória (ou punitiva) e outra preventiva (ou dissuasora). ${ }^{22}$
\end{abstract}

Segundo o jurista catarinense, ainda que a função precípua da responsabilidade civil seja a reparatória, umbilicalmente ligada ao seu próprio conceito, ao lado dela é oportuna a análise também das funções punitiva e preventiva.

Fernando Noronha destaca que só tem sentido falar em função sancionatória da responsabilidade civil quando se tratar de responsabilidade subjetiva, porquanto estaria relacionada tão somente a um juízo de censura ou reprovabilidade na conduta do agente provocador do dano, vislumbrado apenas com a presença do dolo ou da culpa. ${ }^{23}$

\title{
3.1. FUNÇÃO PREVENTIVA DA RESPONSABILIDADE CIVIL
}

Hodiernamente a responsabilidade civil se funda não só na ideia de "reparação" ou regresso ao status quo ante, mas sobretudo na de proteção aos direitos das vítimas - e das potenciais vítimas - de danos provocados.

Nesse sentido, vem ganhando espaço a concepção segundo a qual a função precípua da responsabilidade civil deixa de ser a função reparatória e passa a ser a preventiva. ${ }^{24}$

Com efeito, a partir da ideia de proteção aos bens jurídicos individuais e coletivos, não é difícil constatar que é preferível que o sistema jurídico, em vez de

$\begin{array}{ll}22 & \text { NORONHA, 2007, p. } 436 . \\ 23 & \text { Ibid.; p. 437. } \\ 24 & \text { VENTURI, 2012, p. } 55 .\end{array}$


focar na reparação dos danos, incentive a adoção de medidas para preveni-los, mormente aqueles de caráter extrapatrimonial, que são de difícil ou impossível reparação.

Em tese de doutorado apresentada em 2012, Thais Venturi trata da função preventiva da responsabilidade civil e a relaciona com a Análise Econômica do Direito. A agora doutora ressalta que "a premissa fundamental lançada pelo referido movimento nesse campo do Direito ressalta que a primeira função das regras de responsabilidade é a de influenciar no comportamento futuro, tanto dos potenciais agressores como das eventuais vítimas". ${ }^{25}$

Com efeito, o sistema de regras de responsabilidade civil tem o papel de induzir determinados comportamentos por parte de agentes que desempenhem atividades que envolvam determinados riscos, de modo a internalizá-los e adotar precauções necessárias visando neutralizá-los e evitá-los.

\section{A IDEIA DE PREVENÇÃo NA RESPONSABILIDADE CIVIL E A ANÁLISE ECONÔMICA DO DIREITO}

A partir da década de 60 do século XX, um dos precursores da Análise Econômica do Direito, Guido Calabresi, ao tratar da responsabilidade civil focado nos "custos dos acidentes", teceu sérias críticas ao sistema de responsabilidade civil norte-americano fundado na culpa. ${ }^{26}$

O autor americano, utilizando-se de premissas tanto do Direito quanto da Economia, defende a adoção um sistema de responsabilidade ordenado a partir de regras simples e claras, concebidas à luz do princípio do menor custo de transação (ou cheapest cost avoider). ${ }^{27}$

\footnotetext{
25 Ibid., p.126.

26 VENTURI, 2012, p. 128.

$27 \quad$ Ibid.; p. 128.
} 
Significa que, de forma objetiva, a responsabilidade civil deveria recair justamente sobre o agente que poderia ter evitado acidentes a custos menores, adotando medidas preventivas, mas não o fez. Nesta esteira, Thais Venturi desenvolve o raciocínio do autor americano da seguinte forma:

\begin{abstract}
Considerando que as normas de responsabilidade civil atuam como sistema de incentivos à adoção de condutas preventivas pelas partes envolvidas em situação de risco, CALABRESI já apontava a existência de ao menos cinco fundamentos para validar o emprego de meios de prevenção em um sistema de responsabilidade civil, concernentes: I) à ignorância dos particulares a respeito do que mais lhes convém; ii) aos custos de acidentes não reduzíveis a dinheiro; iii) aos juízos morais envolvidos; iv) às limitações intrínsecas à teoria da repartição dos recursos e $v$ ) à necessidade de a prevenção influenciar, eficazmente, sobre certas atividades e atos. ${ }^{28}$
\end{abstract}

A partir do momento em que a reparação dos danos se torna mais onerosa aos agentes econômicos que a prevenção de sua ocorrência, criando-se mecanismos econômicos e jurídicos para a adoção de medidas de precaução, em detrimento da reparação de danos, é razoável inferir que esses agentes, atuando sempre no sentido de maximizar seus ganhos e reduzir seus prejuízos e suas despesas, optem por aquela, o que, consequentemente, acarretará na diminuição da ocorrência e da gravidade dos danos.

Desta feita, a partir do instrumental oferecido pela escola de Direito e Economia é possível desenvolver formas de criar incentivos para que os sujeitos envolvidos em determinadas atividades adotem medidas destinadas à prevenção de danos e amenização de riscos.

\title{
5. CONCLUSÃO
}

Durante o século $X X$, presenciou-se tanto no direito pátrio como no direito estrangeiro, não sem certa resistência por parte da doutrina mais tradicional, a 
abertura para a objetivização da responsabilidade civil. Não há dúvidas de que essa mudança de paradigma na responsabilidade civil representou salutar evolução na proteção aos direitos individuais e coletivos, sobretudo diante das mudanças sociais e econômicas da sociedade moderna.

Entretanto, em boa hora vem se notando outra importante mudança da orientação da responsabilidade civil como instituto destinado à reparação de danos para concepção de prevenção e internalização de riscos por parte dos agentes envolvidos em determinadas atividades. Mais do que isso, trata-se da alteração da responsabilidade civil focada em danos do passado para uma responsabilidade civil destinada a (estimular e desestimular) comportamentos futuros. E para tanto, faz-se imprescindível a utilização do instrumental teórico fornecido pela Escoa de Direito e Economia.

Se a complexidade do mundo verificada a partir do século XX exigiu uma mudança no paradigma da responsabilidade civil, ensejando a adoção da responsabilidade objetiva em diversas áreas, a sociedade atual, principalmente tendo em vista o sistema protetivo de direitos individuais e coletivos erigidos pela Constituição Federal da República de 1988, exige a adoção de medidas com vistas não só à justa reparação por danos causados, mas principalmente à sua prevenção ou atenuação.

\section{REFERÊNCIAS}

CAVALIERI FILHO, Sérgio. Programa de Responsabilidade Civil. $10^{\underline{a}}$ ed. São Paulo: Editora Atlas, 2012.

COSTA, Ilton Garcia da; ZOLANDECK, Willian Cleber. A responsabilidade civil do Estado por erro judiciário. Revista Juridica, [S.I.], v. 1, n. 28, p. 210-229, nov. 2012. ISSN 2316-753X.

em: <http://revista.unicuritiba.edu.br/index.php/RevJur/article/view/426/331>. Acesso em: 17 abr. 2020. doi:http://dx.doi.org/10.21902/revistajur.2316-753X.v1i28.426. 
DI PIETRO, Maria Sylvia Zanella. Direito Administrativo. 24르 ed. São Paulo: Editora Atlas, 2011.

GOMES, Orlando. Culpa x Risco. Revista de Direito Civil Contemporâneo. V. 11. Abr - Jun, 2017, p. 349 - 358.

MIRAGEM, Bruno. Curso de Direito do Consumidor. $4^{\text {a }}$ ed. São Paulo: Editora Revista dos Tribunais, 2013.

NORONHA, Fernando. Direito das Obrigações: Fundamentos do Direito das Obrigações; Introdução à Responsabilidade Civil, v.1 $2^{\underline{a}}$ Ed. São Paulo: Editora Saraiva, 2007.

TARTUCE, Flávio. Direito Civil: Direito das Obrigações e Responsabilidade Civil. v. 2. 12 a ed. Rio de Janeiro: Editora Forense, 2016.

TARTUCE, Flávio; NEVES, Daniel Amorim Assumpção. Manual de Direito do Consumidor: Direito Material e Processual. 4aㅡ ed. São Paulo: Ed. Método, 2015, p. 132.

VENOSA, Sílvio de Salvo. Direito Civil: Responsabilidade Civil. 4⿳亠丷a ed. São Paulo: Atlas. 2004.

VENTURI, Thais Gouveia Pascoaloto. A Construção da Responsabilidade Civil Preventiva no Direito Civil Contemporâneo, 2012, 425 f. Tese de Doutorado em Direito das Relações Sociais. Faculdade de Direito da Universidade Federal do Paraná, Curitiba, 2012. 